\title{
Clinical and epidemiological characterization of patients receiving home care in the city of Maceió, in the state of Alagoas, Brazil
}

\author{
Carla Montenegro Dâmaso Carnaúba' \\ Thaysa Dayse Alves e Silva² \\ Juliana Felizardo Viana² \\ Júlia Badra Nogueira Alves ${ }^{2}$ \\ Natália Lima Andrade² \\ Euclides Maurício Trindade Filho?
}

\section{Abstract}

Objective: To clinically and epidemiologically characterize patients receiving home care in the city of Maceio, in the state of Alagoas, Brazil. Methods: An observational, crosssectional study with a sample of 859 patients was carried out, based on data obtained from the medical records of institutions that provide a home care service. A total of 445 patients were from a public service and 414 were from a private service. Descriptive analysis was used for the demographic, clinical and functional variables. Results: Most patients were elderly, female, bedridden, fed orally and had neurological disorders, with stroke the most common diagnosis. Regarding patient evolution, 16.8\% of individuals were discharged from home care, $45 \%$ of patients died and $24 \%$ were hospitalized during the period of home care. A total of $9 \%$ of patients had a tracheostomy, $84.7 \%$ breathed room air, 9.3\% used oxygen, 4\% used noninvasive mechanical ventilation, $1.9 \%$ used invasive mechanical ventilation, and $24.9 \%$ of patients had pressure ulcers. All patients received medical visits, with 693 receiving nursing care, 767 undergoing physiotherapy, 233 receiving speech therapy sessions, 665 patients accompanied by a nutritionist, 64 undergoing occupational therapy sessions and 98 receiving counseling. Conclusion: It was noted that some results differed from literature and between the public and private service. This divergence could be related to the specific epidemiology of each region and the type of insurance paying for care (Unified Health Service or Private).

\footnotetext{
1 Centro Universitário CESMAC, Departamento de Ciências Biológicas. Maceió, AL, Brasil.

2 Centro Universitário CESMAC, curso de medicina. Maceió, AL, Brasil.
}

Keywords: Home Nursing. Epidemiological Profile. Elderly. 


\section{INTRODUCTION}

The present study emerged from the expansion in home care in Brazil. The main aim of this modality of care is to de-hospitalize chronic, stable patients in order to vacate hospital beds, and subsequently to reduce hospital overcrowding and minimize some of the biggest problems inherent in existing health systems, especially the public health system ${ }^{1,2}$.

The term "home care" can be defined as a set of potential hospital procedures to be carried out in the home of the patient, and includes health actions developed by a multi-professional team ${ }^{3}$. Use of this model is growing throughout Brazil and it has emerged as a new workplace for health professionals ${ }^{3}$.

This care modality has been recurrently recommended to meet the needs of people with chronic illnesses and diseases that lead to dependency, based on values such as family coexistence and affection, as well as the presumption of a better quality of life for the patient and, obviously, a reduction in costs related to hospital beds ${ }^{4,5}$.

The objectives of this type of home care service are: to contribute to the optimization of hospital beds; reduce hospital admission costs; reduce the risk of nosocomial infection; reintegrate the patient into their family and support nucleus; provide humanized and comprehensive care; improve the patient's quality of life; avoid readmissions; reinsert the patient into society; preserve patient autonomy; stimulate the increased participation of the patient and their family in the proposed treatment ${ }^{6,7}$.

It is therefore necessary to understand the epidemiological profile of the population receiving home care to develop techniques that best fit and meet the specific needs of patients. The present study aimed to clinically and epidemiologically characterize patients undergoing home care in the city of Maceió. The specific objectives were: demographically characterize patients undergoing home care; identify the main diseases that motivate home care; analyze the outcomes of home care; identify the level of dependency of patients in home care; characterize the composition of the multidisciplinary team; identify the presence of hospitalizations and decubitus ulcers; analyze the feeding and breathing routes and compare the profiles of patients receiving care in the public and private systems.

\section{METHOD}

An observational and cross-sectional study was performed. Data were collected in the records departments of institutions that provide home care services in the municipal region of Maceió, in the state of Alagoas, Brazil: Clinilar, NIAD (Núcleo Interdisciplinar de Assistência Domiciliar (Interdisciplinary Home Care Center)) and SAD (Serviço de Atenção Domiciliar (the Home Care Service)). The city of Maceió, the capital of Alagoas, has a population of 936,314 inhabitants, approximately 66,470 of whom are elderly, and life expectation in the state is 67.2 years.

The SAD (public) is part of the activities of the Municipal Secretary of Maceió, Alagoas, and provides suitable, free multi-professional care to patients of low to medium complexity. Those that require more complex treatment, such as mechanical ventilation or the 24-hour presence of a nurse, are not included in the program.

Clinilar and NIAD are private companies that offer a home care service in Maceió, Alagoas. The services offered are provided by a multi-professional team, composed of qualified health professionals trained to carry out both simple and complex procedures, capable of installing a structure similar to an ICU bed and even offering 24 -hour nursing care. These companies provide care either on a private or health plan basis.

The sample size was calculated as 879 patients, using the equation below for finite populations and based on the following criteria: a) a total number of patients in home care of 1,950; B) a 95\% confidence interval, expressed as a standard deviation of 1.96; C) a sample error of $5 \%$; D) a prevalence of $80 \%$. The prevalence estimate of $80 \%$ was adopted based on a pilot study in which the medical records of 30 patients were randomly evaluated, taking as a reference the proportion of elderly patients.

$$
\mathrm{n} \frac{\sigma^{2} p \cdot q \cdot N}{e^{2}(N-1)+\sigma^{2} p \cdot q}
$$


The medical records of all patients inserted in the Home Care Programs of three institutions in the municipal region of Maceió, Alagoas, during the period from January 2011 to December 2015, were included in the study. Medical records containing a large quantity of incomplete and/or illegible were excluded.

A data collection instrument was developed that contained the following variables: name, age, gender, main diagnosis, degree of dependence in walking, breathing route, feeding route, use of ventilatory support, presence of pressure ulcers, hospital discharges and hospitalizations. As the study was retrospective, many patients had already been discharged from home care and many had died.

The study was approved by the Research Ethics Committee of the Centro de Estudos Superiores de Maceió (the Maceió Higher Level Studies Center) (CESMAC), under approval number 1.252.375. The waiver of free and informed consent was requested, as the study was retrospective and the data were collected from the records of the institutions.

The quantitative variables were presented as mean, median and standard deviation. The qualitative variables were presented in frequency tables.

\section{RESULTS}

Of the 879 medical records collected from the institutions providing home care services, 20 were excluded as their data was incomplete. Thus, the final sample of the study consisted of 859 patients, of whom 445 were from a public home care service and 414 were from private services. The majority of the patients were female (56.9\%) and most were elderly, with a mean age of $72.62( \pm 18.28)$ and a median of 78 years. The most frequent age group was that over 79 years (44\%), a result that was similar in both the private and public institutions.

In terms of the diagnosis variable, neurological diseases were most frequent in home care, with $61.1 \%$, followed by oncological diseases, with $6.5 \%$. Neurological diseases $(64.7 \%)$ were also the most common, followed by endocrine diseases $(10.5 \%)$ and orthopedic diseases (8.7\%), in the public institution. In the private institutions, the most frequent causes that led to home care were neurological diseases $(57.2 \%)$, followed by oncological diseases $(8.9 \%)$ and orthopedic diseases (3.8\%).

Some medical records did not present a single pathology, but instead the interaction of several pathologies that acted concomitantly in the body, and therefore presented more than one diagnosis.

With regard to the evolution of the patient, 145 $(16.8 \%)$ patients were discharged from home care, $386(45 \%)$ patients died and $206(24 \%)$ patients were hospitalized during the period of home care (Table 2). Of the 145 patients who were discharged, 124 were from public institutions and only 21 patients were from private institutions.

Table 1. Sociodemographic characteristics of patients undergoing home care. Maceió, Alagoas, 2011-2015.

\begin{tabular}{llll}
\hline Variable & $\mathrm{n}(\%)$ & Public (\%) & Private $(\%)$ \\
\hline Gender & & & \\
Female & $489(56.9)$ & $247(55.5)$ & $242(58.5)$ \\
Male & $370(43.1)$ & $198(44.5)$ & $172(41.5)$ \\
\hline Age range (years) & & & \\
$0-19$ & $14(1.6)$ & $6(1.3)$ & $8(1.9)$ \\
$20-39$ & $50(5.8)$ & $20(4.5)$ & $30(7.2)$ \\
$40-59$ & $83(9.6)$ & $35(7.8)$ & $48(11.6)$ \\
$60-79$ & $308(36)$ & $188(42.2)$ & $120(29)$ \\
Over 79 & $378(44)$ & $185(41.6)$ & $193(46.6)$ \\
Age not given & $26(3)$ & $11(2.5)$ & $15(3.6)$ \\
\hline
\end{tabular}


Table 2. Characteristics of diagnosis. Maceió, Alagoas, 2011-2015

\begin{tabular}{llll}
\hline Variable & $\mathrm{n}(\%)$ & Public $(\%)$ & Private $(\%)$ \\
\hline Diagnosis & & & \\
Neurological diseases & $526(61.1)$ & $288(64.7)$ & $237(57.2)$ \\
Oncological diseases & $56(6.5)$ & $19(4.3)$ & $37(8.9)$ \\
Orthopedic diseases & $55(6.4)$ & $39(8.7)$ & $16(3.8)$ \\
Endocrine diseases & $48(5.6)$ & $47(10.5)$ & $1(0.2)$ \\
Pulmonary diseases & $20(2.3)$ & $7(1.6)$ & $13(3.1)$ \\
Heart diseases & $18(2.1)$ & $6(1.3)$ & $12(2.9)$ \\
Rheumatic diseases & $12(1.4)$ & $8(1.8)$ & $4(0.9)$ \\
Hepatic diseases & $7(0.8)$ & $1(0)$ & $6(1.4)$ \\
Renal diseases & $6(0.7)$ & $2(4)$ & $4(0.9)$ \\
Psychiatric diseases & $6(0.7)$ & $6(1.3)$ & $0(0)$ \\
Others & $19(2.2)$ & $18(4)$ & $1(0.2)$ \\
No information & $104(12.1)$ & $12(2.7)$ & $92(22.2)$ \\
\hline
\end{tabular}

In terms of specific diagnosis, strokes were the most frequent cause of the patient seeking the home care service, with $35.2 \%$, followed by dementia (9.4\%) and neoplasia (5.8\%) (Table 3).

Regarding the clinical and functional characteristics of patients cared for in the home, bedridden patients (non-ambulatory) represented the majority of the sample (72.5\%). Patients who depended on third parties to walk represented $19.5 \%$, while patients were not dependent for walking made up $3 \%$ of the sample. An interesting fact was that of the 26 patients who walked independently, 22 were from the public sector and only four were from private services.

In terms of the feeding route, 538 patients (64\%) were orally fed, 134 (15.6\%) were fed via gastrostomy, 132 patients $(15.3 \%)$ were fed by nasoenteral catheter (NEC) or nasogastric catheter (NGC) and only five patients $(0.6 \%)$ underwent parenteral nutrition. Another significant fact was that the prevalence of NEC or NGC was greater than the use of gastrostomy in the public sector, something which did not occur in the private service.

A total of $9 \%$ of patients (78) were tracheostomized. It was observed that the majority of tracheostomized patients and who underwent gastrostomy were from the private service, while only eight and nine patients, respectively, were from the public service.

Most patients (84.7\%) breathed room air, 9.3\% used oxygen, and 4\% used Non-Invasive Mechanical Ventilation or Invasive Mechanical Ventilation.

In relation to the presence of pressure ulcers, 214 of patients (24.9\%) had some type of ulcer (Table 4), the majority of whom were from the public sector. 
Table 3. Characteristics based on specific diagnosis. Maceió, Alagoas, 2011-2015.

\begin{tabular}{llll}
\hline Diagnosis & $\mathrm{n}(\%)$ & Public $(\%)$ & Private $(\%)$ \\
\hline Stroke & $303(35.2)$ & $186(41.8)$ & $117(28.2)$ \\
Dementia & $81(9.4)$ & $37(8.3)$ & $44(10.6)$ \\
Neoplasm & $50(5.8)$ & $15(3.3)$ & $35(8.4)$ \\
Decompensated Diabetes & $48(5.6)$ & $47(10.5)$ & $1(0.2)$ \\
Fractures & $38(4.4)$ & $31(7)$ & $7(1.7)$ \\
Parkinson's & $29(3.3)$ & $15(3.3)$ & $14(3.4)$ \\
Neuromuscular diseases & $23(2.6)$ & $2(0.4)$ & $21(5)$ \\
Spinal cord injury & $21(2.4)$ & $13(2.9)$ & $8(1.9)$ \\
Traumatic brain injury & $19(2.2)$ & $9(2)$ & $10(2.4)$ \\
Polytrauma & $14(1.6)$ & $6(1.3)$ & $8(1.9)$ \\
Cardiac insufficiency & $14(1.6)$ & $6(1.3)$ & $8(1.9)$ \\
Hypoxic encephalopathy & $12(1.4)$ & $0(0)$ & $12(2.9)$ \\
Chronic obstructive pulmonary disease & $11(1.3)$ & $1(0.2)$ & $10(2.4)$ \\
Arthrosis & $9(1)$ & $6(1.3)$ & $3(0.7)$ \\
Others & $83(9.6)$ & $59(13.2)$ & $24(5.8)$ \\
No information & $104(12.1)$ & $12(2.7)$ & $92(22.2)$ \\
\hline
\end{tabular}

Table 4. Medical and functional characteristics of patients undergoing home care. Maceió, Alagoas, 2011-2015.

\begin{tabular}{|c|c|c|c|}
\hline Variable & $\mathrm{N}(\%)$ & Public $(\%)$ & Private $(\%)$ \\
\hline \multicolumn{4}{|l|}{ Levels of dependency } \\
\hline Does not walk (restricted to bed) & $623(72.5)$ & $322(72.3)$ & $301(72.7)$ \\
\hline Walks with dependency & $168(19.5)$ & $97(21.7)$ & $71(17.1)$ \\
\hline Walks without dependency & $26(3)$ & $22(4.9)$ & $4(0.9)$ \\
\hline No information & $42(4.9)$ & $4(0.9)$ & $38(9.1)$ \\
\hline \multicolumn{4}{|l|}{ Feeding route } \\
\hline Oral & $538(64)$ & $393(88.3)$ & $145(35)$ \\
\hline Gastrostomy & $134(15.6)$ & $9(2)$ & $125(30.2)$ \\
\hline Nasal catheter (enteral or gastric) & $132(15.3)$ & $40(9)$ & $92(22.2)$ \\
\hline Parenteral & $5(0.6)$ & $0(0)$ & $5(1.2)$ \\
\hline No information & $50(5.8)$ & $3(0.7)$ & $47(11.3)$ \\
\hline \multicolumn{4}{|l|}{ Use of tracheostomy } \\
\hline No & $781(91)$ & $437(98.2)$ & $344(83)$ \\
\hline Yes & $78(9)$ & $8(1.8)$ & $70(16.9)$ \\
\hline \multicolumn{4}{|l|}{ Ventilatory support } \\
\hline Room air & $728(84.7)$ & $439(98.6)$ & $289(69.8)$ \\
\hline Oxygen therapy & $80(9.3)$ & $6(1.3)$ & $74(17.8)$ \\
\hline Non-invasive mechanical ventilation & $35(4)$ & $0(0)$ & $35(8.4)$ \\
\hline Invasive mechanical ventilation & $16(1.9)$ & $0(0)$ & $19(0.4)$ \\
\hline \multicolumn{4}{|l|}{ Presence of pressure ulcer } \\
\hline Yes & $214(24.9)$ & $133(29.9)$ & $81(19.5)$ \\
\hline No & $645(75)$ & $312(70.1)$ & $333(80.4)$ \\
\hline
\end{tabular}


All patients received medical visits, as the doctor was the professional responsible for the prescription of medication. The data referring to the number of patients attended by a multidisciplinary team are shown in Table 5. It is striking that all patients in the private service underwent physiotherapy sessions, and only one patient did not receive a visit from a nutritionist.

Table 5. Number of patients treated by multi-professional care team. Maceió, Alagoas, 2011-2015.

\begin{tabular}{llll}
\hline Variable & $\mathrm{N}(\%)$ & Public $(\%)$ & Private $(\%)$ \\
\hline Doctor & $859(100)$ & $445(100)$ & $414(100)$ \\
Physiotherapist & $767(89.3)$ & $353(79.3)$ & $414(100)$ \\
Nursing & $693(80.6)$ & $321(72.1)$ & $372(89.8)$ \\
Nutritionist & $665(77.4)$ & $252(56.6)$ & $413(99.7)$ \\
Speech Therapist & $233(27.1)$ & $79(17.7)$ & $154(37.1)$ \\
Psychologist & $98(11.4)$ & $41(22.4)$ & $57(13.7)$ \\
Occupational Therapist & $64(7.4)$ & $44(9.9)$ & $20(4.8)$ \\
\hline
\end{tabular}

\section{DISCUSSION}

The sociodemographic characteristics of the patients studied were compatible with literature regarding the population of home care programs $1,2,8,9$. Elderly persons aged over 79 years made up the most prevalent age range, with this group and other age ranges over 60 years representing $80 \%$ of the sample, showing that home care is mainly aimed at a geriatric population. Benassi et al. ${ }^{2}$, in a study of the epidemiological profile of patients undergoing physiotherapy as part of a home care program in the city of São Paulo, found that the most prevalent age group was that between 71 and 90 years. A study by Góis ${ }^{9}$ identified a similar result in terms of age, with the 70 to 89 year range predominating. An age over 80 years was most prevalent in the studies by Martelli et al. ${ }^{1}$ and Del Duca et al. ${ }^{10}$, while a similar result was found in the home care program of the Hospital Público de Santa Maria (Santa Maria Public Hospital) (Rio Grande do Sul) ${ }^{8}$. The target population in an Austrian study of the home care population by Kamenski et al. ${ }^{11}$, was composed in the majority (more than two thirds) by women, and the mean age was 80 years.

This predominance can be explained by the fact that this age group (over 60 years) includes severe levels of disability, generated by the evolution of chronic diseases. Home care has grown among the elderly in comparison with other types of care, and now represents $72 \%$ of health plan beneficiaries ${ }^{12}$.

This prevalence is explained by the process of demographic transition that Brazil is undergoing and by the increase in the number of chronic diseases among this population. The disorders that occur during the aging process can be ameliorated by actions that promote health and assist in the maintenance of the functional capacity of the elderly person. As such, home care programs represent one of the alternatives incentivized by the Brazilian government when facing such demand ${ }^{12}$.

In terms of gender, women predominated, a finding similar to the majority of studies carried out on home care $e^{1,2,9,10,12-14}$. This fact can be explained by the results of the IBGE survey ${ }^{15}$. When observing the ratio between the genders by age group in Brazil, the ratio of gender was over 100 up to the 20 to 24 year age group, indicating an excess of men in the population. For age groups over 25 years, however, there was an excess of women, and in the group aged over 60, the indicator was 80 men for every 100 women.

The mortality index is greater among men than among women, meaning the female population is larger. The over-mortality of male adults and young elderly men and the subsequent "feminizing" of the 
elderly population result, therefore, from greater rates of mortality from diseases of the circulation and other illnesses associated with smoking, such as neoplasias and CPOD (Chronic Obstructive Pulmonary Disease), alcoholism (some digestive neoplasias and alcoholic liver disease) and external causes (violent deaths and traffic accidents), among $m^{16}{ }^{16}$. Life expectancies upon reaching 80 years of age in 2015 were 10.1 and 8.4 years for women and men, respectively ${ }^{17}$.

According to the IBGE census ${ }^{15}$, the population in the municipal region of Maceió, Alagoas is predominantly female. The predominance of women may also reflect the unequal increase of life expectancy between the sexes, which is more significant among women than men, and can be attributed to biological factors and/or unequal exposure to risk factors for health.

Neurological disturbances were the most frequent, affecting 61.15 of patients, followed by oncological diseases, which affected $6.5 \%$ of patients. Strokes were the neurological disturbances that appeared most frequently as the main motive for being referred for home care $(35.2 \%)$, both in the public $(41.8 \%)$, and the private $(28.2 \%)$ sectors.

It is important to note that the diagnoses varied when the public (SAD) and the private (NIAD and CLINILAR) services were compared, which can be explained by the greater complexity of the health profile of patients in the private service, as the SAD service of the municipal region of Maceió does not provide care to high complexity patients who require special equipment and procedures.

A similar result was found in the study by Fabrício et $a 1 .^{18}$, where the most prevalent diagnosis was neurological disease $(27 \%)$, followed by neoplasias $(17 \%)$. In the study by Aguiar ${ }^{19}$, the majority of patients suffered from neurological diseases $(68.7 \%)$, followed by endocrine-metabolic illnesses $(64.8 \%)$.

In the study by Brondani et al. ${ }^{20}$ of patients from a Home Care Service in Rio Grande do Sul, the most prevalent diagnosis was strokes (26.3\%), followed by neoplasias (18\%). The most common conditions of users of a Programa de Internamento Domiciliar (Home Hospitalization Program) (PID), in Monte Claros, in the state of Minas Gerais, were pneumonia (16.1\%) and diabetes Mellitus (6.6\%) ${ }^{1}$. In the study by Gargano et al. ${ }^{8}$, the main illnesses were respiratory disease (35.5\%) and complications from neoplasias $(12 \%)$.

This high prevalence of neurological diseases can be explained by the fact that the volume and weight of the brain decrease with age, at a rate of close to $5 \%$ per decade over the age of 40 , with an increase in the rate of this decline from the seventh decade of life onwards. This fact makes the elderly person more predisposed to a series of clinical conditions with neurological repercussions ${ }^{21}$.

In Brazil, strokes are the leading cause of hospitalization, mortality and disability, even surpassing cancer and heart disease ${ }^{15,22,23}$. The results of some of the studies above varied, a finding which may be explained by the conditions identified being related to the specific epidemiology of each location, and may also be related to the type of health insurance provider, such as the Sistema Único de Saúde (the Unified Health System) (SUS) or private health insurance. For example, the SUS does not support patients who require mechanical ventilation in the home environment, meaning that the provision of such treatment must be outsourced to services that provide private home care. The same occur with patients who need continuous monitoring with 24-hour nursing professionals. This situation may explain the lower complexity of public service patients, and may explain the variation in diagnosis.

Regarding the outcomes of the studied population, death was the main reason for ending the Home Care Program. This can be explained by the clinical profiles involved, where chronic conditions associated with several comorbidities and sequelae prevail, which cause great dependence and dysfunctionality for the individual.

In terms of hospitalization, similar results were obtained between the two services, with $24 \%$ of patients being hospitalized during the home care program.

Rehospitalization is an important indicator of quality of care, and a good thermometer for the degree of resolution of extra-hospital care ${ }^{24}$. 
Therefore, $24 \%$ is considered a low percentage, illustrating the effectiveness of the home services studied. However, no official parameters have yet been disclosed, which are capable of indicating the number of rehospitalizations expected for patients assisted by home care.

Regarding patient discharge, of the 145 patients discharged, 124 were from the public institution and only 21 patients were from private institutions. This can be explained by the fact that SUS home care is aimed at the care of patients with more specific care needs, resulting in high levels of patients requiring this service and a large turnover. Another important factor is the lower degree of complexity in SUS patients, who are subsequently more likely to be discharged.

Discharge represents a positive outcome of home care, and can demonstrate the effectiveness of the program, as discharge is often necessary to improve the clinical condition ascertained at admission ${ }^{20}$. Therefore, as the research was carried out based on medical records, it is difficult to identify the true reason for discharge, as it is believed that besides clinical improvement, there are other factors that affect discharge from home care, including: the need for rotation in the SUS service, due to high demand; interference from the health plan; discharge at the request of the family, who often do not adapt to the home care service, describing, among other factors, interference of their privacy.

The predominant level of dependence was "bed restricted" or, better, completely bedridden, which affected $72.5 \%$ of the patients. Most patients in both the public service and the private service were bedridden. The major difference was among patients who walked independently, of whom 22 were in the public service and only four were in the private service, a fact that can be explained by the lower degree of complexity of the public service patients.

The study by Góis ${ }^{9}$, which found that 37.8\% of the patients undergoing home physiotherapy had a severe disability and were restricted to bed (completely bedridden) while 52\% were dependent on third parties for walking, and the other $9.2 \%$ were wheelchair users or walked independently. In the same study, the authors found an association between age and level of patient limitation. This discrepancy in results can be explained by the fact that in the study by Góis ${ }^{9}$ the home care provided was physiotherapy, and thus aimed at a different public; the percentage of patients with neurological disease was much lower than that found in the present study, a fact that can be justified by the greater level of mobility among these patients, as neurological conditions are the diseases that cause the greatest motor impairment.

In the study by Biscione et al. ${ }^{14}$, conducted with 2,934 patients enrolled in a home care program in Belo Horizonte (Minas Gerais), it was found that degree of dependence varies according to the degree of complexity of the patients, with the greater the degree of complexity, the greater the degree of dependence, and where $53 \%$ of patients with high complexity were totally dependent. In the study by Bastos et al..$^{13}$, it was observed that most patients $(50 \%)$ walked with help, $25 \%$ were bedridden, $15 \%$ walked independently and only $10 \%$ were wheelchair users. The difference between the results of the Bastos study and the present study can be explained once again by the type of care (public or private), as in the study by Bastos et al. ${ }^{13}$ the service was exclusively public.

Therefore, the degree of limitation may vary according to the population studied, the type of care (public or private) and the degree of patient complexity.

With regard to feeding route, the present study demonstrated that most of the patients were fed orally $(64 \%)$. However, when the services were analyzed in isolation, a divergence between the results was observed, with $88.3 \%$ in the public service fed orally and the majority in the private service (52.4\%) fed by means of catheters. Another important finding of the present study is that when comparing the use of catheters in the two services, the prevalence of NEC or NGC was greater than the use of gastrostomy in the public service, whereas the use of gastrostomy was greater than the use of nasal catheters in the private service.

The lower use of gastrostomy in the SUS may be due to the high cost of this procedure, when compared to access via NEC or NGC, and also the difficulty of carrying out this surgical procedure 
within the SUS. These factors were possibly responsible for the higher prevalence of the nasal route in the public service.

In the study by Biscione et al. ${ }^{14}$, most of the patients were also fed orally. In the study by Gaspar et al. ${ }^{25}$, in which the profile of patients treated by the Programa Saúde da Família (Family Health Program) (PSF) in the city of São Paulo was evaluated, only $1.2 \%$ of the patients used some type of catheter (gastrostomy or nasoenteral). In the study by Aguiar ${ }^{19}$, however, the majority of patients $(52.5 \%)$ were fed by gastrostomy, $42.5 \%$ by the oral route and $5 \%$ by NEC. The study by Azank et al. ${ }^{26}$, found that $73.3 \%$ of the patients received food via nasoenteric catheter (NEC) and $26.6 \%$ were fed by gastrostomy (GT). In the study by Brondani et al. ${ }^{20}, 73.7 \%(\mathrm{n}=42)$ of patients required devices (gastrostomy or nasoenteral catheter) to supplement feeding or as an exclusive route of feeding.

In relation to tracheostomy, of the 78 patients who were tracheostomized, 70 were from private services. The same behavior occurred for the use of oxygen and mechanical ventilation, in which the prevalence is much higher in private services (home-care).

The SAD service in Maceió, Alagoas does not offer oxygen and mechanical ventilation to patients. Patients with chronic dependence on mechanical ventilation and oxygen therapy are usually hospitalized for an extended period of time, some until their death, while others are able to enter the private home care service through the state.

In a study by Lima et al. ${ }^{27}$ on intensive home care through the SUS, results revealed that the route to obtain life support are filled with obstacles and that the search for home care through the dynamics of the SUS involves bureaucracy, professionals and equipment that, in many situations, hinder the access of the population.

Also in relation to the devices used by the patients, in the study by Brondani et al. ${ }^{20}, 24.6 \%$ used tracheostomy. In the study by Watanabe et al. ${ }^{28}$ on the profile of users of prolonged home oxygen therapy, it was observed that $62.6 \%$ of the users had Chronic Obstructive Pulmonary Disease (COPD).

In relation to the presence of pressure ulcers (PU), a prevalence of $24.9 \%$ of patients was observed. In the study by Chayamiti et al. ${ }^{29}, 19.1 \%$ of patients had PUs, and the relationship between increased age and ulcer occurrence was significant. In the study by Nogueira et al. ${ }^{30}$ of patients from a home care program in Spain, $5 \%$ had pressure ulcers.

As for multi-professional assistance, it was observed that doctors, physiotherapists, nurses and nutritionists were the most active professionals in the present study. All patients received medical care. Physiotherapists were the second most frequent profession involved in home visits, and $89.2 \%$ of the patients received physiotherapy sessions.

It is important to emphasize that the multiprofessional team varies according to the type of care (public or private) and the differentiated profile of the patients.

\section{CONCLUSION}

The present study sought to identify the epidemiological profile of patients in home care in the city of Maceió. It was found that the majority of the patients receiving home care are elderly, bedridden, female, and suffer from neurological diseases, with strokes being the most common diagnosis.

It can be observed that some of the results differed between the public and private service. For example, in relation to feeding route, most patients in the public service were fed orally, whereas in the private service most of the patients used feeding tubes.

The study allowed the characterization of the population receiving home care and identified the principle recommendations for the home care service, so that it can be compared with data from other localities and allow specific and effective interventions to improve the service to be carried out. 


\section{REFERENCES}

1. Martelli D, Silva M, Carneiro J, Bonan P, Rodrigues L, Martelli Júnior H. Internação domiciliar: o perfil dos pacientes assistidos pelo Programa HU em Casa. Physis. 2011;21(1):147-57.

2. Benassi V, Leandro J, Medeiros R, Taballi R. Perfil epidemiológico de paciente em atendimento fisioterapêutico em Home Care no Estado de São Paulo. J. Health Sci Inst. 2012;30(4)395-8.

3. Bajotto AP, Witter A, Mahmud SJ, Sirena S, Goldim JR. Perfil do paciente idoso atendido por um programa de atenção domiciliar do sistema único de saúde em Porto Alegre, RS. Rev HCPA. 2012;32(3)311-7.

4. Simão VM, Mioto RCT. O cuidado paliativo e domiciliar em países da América Latina. Saúde Debate. 2016;40(108)156-69.

5. Brasil. Ministério da Saúde. Portaria no 963 , de 27 de maio de 2013. Redefine a Atenção Domiciliar no âmbito do Sistema Único de Saúde (SUS). Diário Oficial da União 16 jul. 2012; Seção 1.

6. Viana S, Alvarenga J, Camargos M, Taciano M, Rafael M. Perfil dos indivíduos avaliados em domicílio pela Fisioterapia nas unidades básicas de saúde de Betim. Rev APS. 2013;16(3):278-86.

7. Pires M, Duarte E, Gottems L, Figueredo N, Spagnol C. Fatores associados à atenção domiciliária: subsídios à gestão do cuidado no âmbito do SUS. Rev Esc Enferm USP. 2013;47(3):648-56.

8. Gargano F, Silveira AE, Nesi A, Bulow AR, Rocha DS, Oliveira DM, et al. Internação domiciliária: uma experiência no sul do Brasil. Rev AMRIGS. 2004;48(2):90-4.

9. Góis ALB. Perfil epidemiológico dos pacientes de fisioterapia domiciliar no Rio de Janeiro [tese]. Rio de Janeiro. Universidade do Estado do Rio de Janeiro, Faculdade de Ciências Médicas; 2010.

10. Del Duca G, Martinez A, Bastos G. Perfil do idoso dependente de cuidado domiciliar em comunidades de baixo nível socioeconômico de Porto Alegre, Rio Grande do Sul. Ciênc Saúde Coletiva. 2012;17(5)1159-65.

11. Kamenski G, Fink W, Maier M, Pichler I, Zehetmayer $\mathrm{S}$. Characteristics and trends in required home care by GPs in Austria: diseases and functional status of patients. BMC Fam Pract. 2016;7(1):55-8.

12. Bruce ML, Mcayay GJ, Raue PJ, BrownEL, Meyers BS, Keohane DJ, et al. Major depression in elderly home health care patients. Am J Psychiatr. 2002;159(8):1367-74.
13. Bastos CC, Lemos ND, Mello AN. Perfil clínicodemográfico dos pacientes inseridos em um programa de assistência domiciliária no município de São Paulo. Rev Kairós. 2007;10(2):205-24.

14. Biscione FM, Szuster D, Ferreira G, Turci MA, Lima Júnior LF, Drumond E, et al. Avaliação de efetividade da atenção domiciliar de uma cooperativa médica de Belo Horizonte, Minas Gerais. Cad Saúde Pública. 2013;29(suppl 1):73-80.

15. Instituto Brasileiro de Geografia e Estatística. XII Censo Demográfico IBGE [Internet]. Rio de Janeiro: IBGE; 2010 [acesso em 26 de jan. 2016]. Disponível em: http://censo2010.ibge.gov.br/

16. Chaimowicz F, Barcelos Em, Madureira MDS, Ribeiro MTF. Saúde do idoso. $2^{a}$ ed. Belo Horizonte: NESCON UFMG; 2013.

17. Instituto Brasileiro de Geografia e Estatística, Diretoria de Pesquisas Coordenação de População e Indicadores Sociais. Tábua completa de mortalidade para o Brasil: breve análise da evolução da mortalidade no Brasil. Rio de Janeiro: IBGE; 2015.

18. Fabrício S, Wehbe G, Nassu F, Andrade J. Assistência domiciliar: a experiência de um hospital privado do interior paulista. Rev Latinoam Enferm. 2004;12(5)721-6.

19. Aguiar N. Análise clínico-epidemiológica dos pacientes internados em "hocare", em Salvador [trabalho de conclusão de curso]. Salvador: Universidade Federal da Bahia, Faculdade de Medicina da Bahia; 2014.

20. Brondani MC, Ramos LH, Lampert M, Seiffert MA, Bruinsma JL, Beuter M. Caracterização de pacientes dependentes de tecnologias de um serviço de internação domiciliar. Rev Enferm UFSM. 2013;3(Esp.):689-99.

21. Esquenazi D, Silva S, Guimarães M. Aspectos fisiopatológicos do envelhecimento humano e quedas em idosos. Rev HUPE. 2014;13(2):11-20.

22. Lessa I, Hage E. O adulto brasileiro e as doenças da modernidade: epidemiologia das doenças crônicas não-transmissíveis. São Paulo: Hucitec; 2007.

23. Oliveira A, Araujo T, Costa A, Morais H, Silva V, Lopes M. Avaliação de pacientes com acidente vascular cerebral acompanhados por programas de assistência domiciliária. Rev Esc Enferm USP. 2013;47(5):1143-9.

24. Paz A, Santos B. Programas de cuidado de enfermagem domiciliar. Rev Bras Enferm. 2003;56(5):538-41. 
25. Gaspar J, Oliveira M, Duayer M. Perfil dos pacientes com perdas funcionais e dependência atendidos pelo PSF no município de São Paulo. Rev Esc. Enferm USP. 2007;41(4):619-28.

26. Azank T, Merhi V, Poliselli C, Oliveira MR. Indicadores nutricionais em pacientes alimentados por sonda, em sistema de "Home Care". ACM Arq. Catarin Med. 2009;38(4):11-8.

27. Lima T, Vargas D, Ambrosina M. Cuidado domiciliar intensivo: uma possível realidade do Sistema Único de Saúde? Rev Bras Enferm. 2004;57(6):658-61.
28. Watanabe CS, Andrade L, Neto M, Santos S, Kawatay L. Oxigenoterapia domiciliar prolongada: perfil dos usuários e custos. Rev Enferm UERJ. 2015;23(1):95-101.

29. Chayamiti E, Caliri MH. Úlcera por pressão em pacientes sob assistência domiciliária. Acta Paul Enferm. 2010;23(1):29-34.

30. Nogueira S, Carvalho A, Melo C, Morais E, Chiari B, Gonçalves M. Perfil de pacientes em uso de via alternativa de alimentação internados em um hospital geral. Rev CEFAC. 2012;15(1):94-104. 